\title{
Encysted peritoneal hydatidosis with a hepatic hydatid cyst
}

D L Kathan, MB ChB, MSc, MBA
S C Griffith-Richards, MB ChB, BSC
(Physiotherapy)
S J Przybojewski, MB ChB, MMed
(Rad D), FCR Diag (SA), Dip Pec (SA)
M Strachan, MB ChB
Y Vadachia, MB ChB
H von Bezing, MB ChB
Department of Radiology, Tygerberg Hospital and
Stellenbosch University

Hydatid disease is an important public health problem in many parts of the world, especially in sheep and cattle farming areas. ${ }^{1}$ Most human cases occur where dogs and livestock are raised together. Echinococcosis or hydatid disease is common in South Africa. It is usually hepatic or pulmonary and usually occurs in children.

This particular case focuses on an adolescent with primary hydatid infection of the liver and spillage into the peritoneum. This resulted in encysted peritoneal hydatidosis. A 14-year-old girl was referred from a secondary level rural hospital with a vague history of lethargy and abdominal distention over a period of many months.

Investigations showed her to have a haemoglobin level of $10 \mathrm{~g} / \mathrm{dl}$ and positive echinococcosis serology

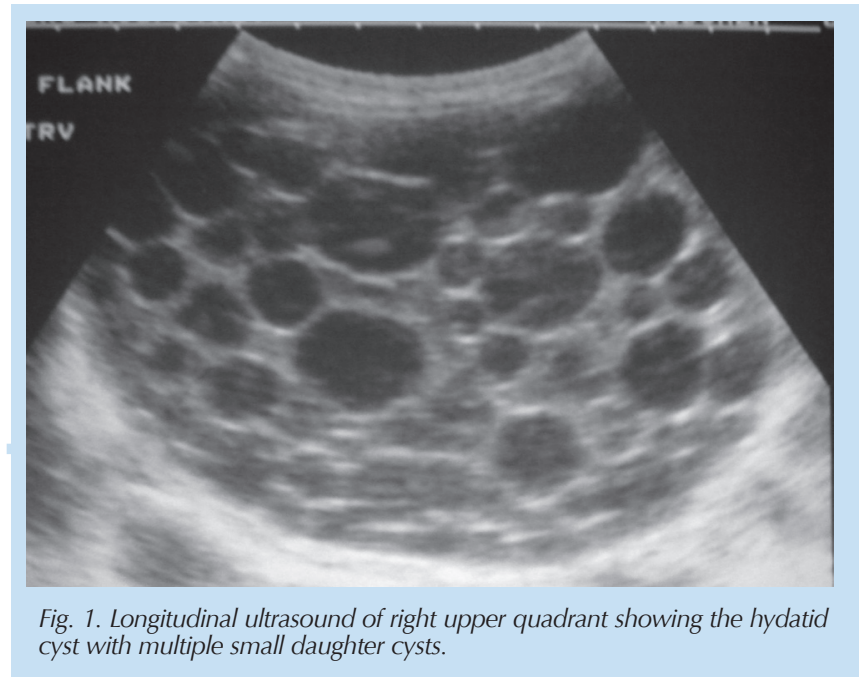

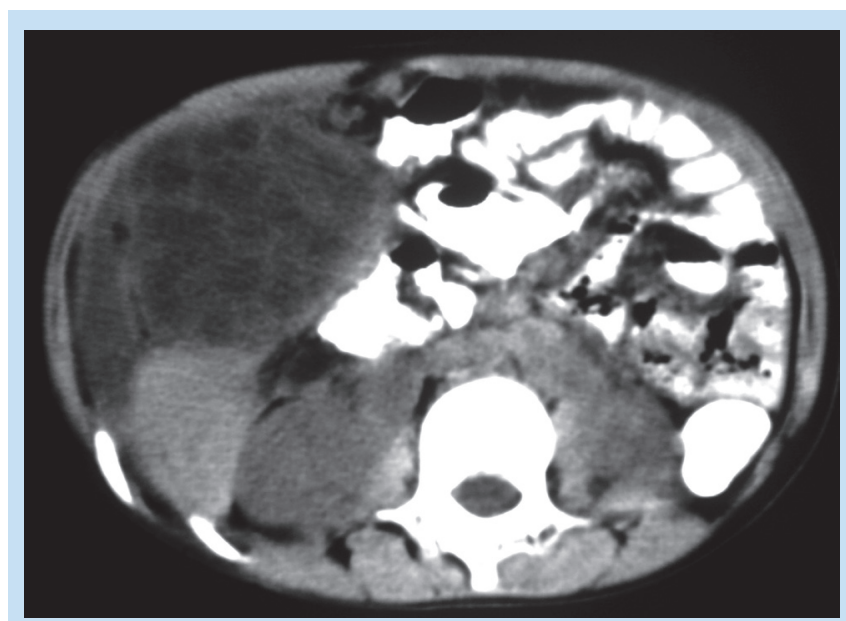

Fig. 2. a. Axial contrasted CT scan demonstrates the hepatic hydatid cyst with internal daughter cysts/brood capsules.

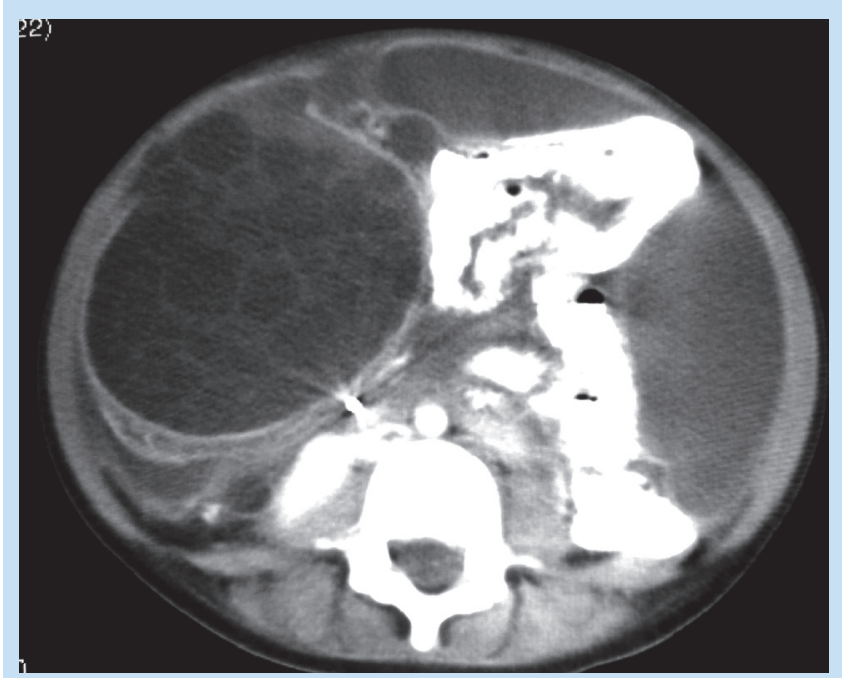

Fig.2b. The hydatid cyst projects beyond the liver margin inferiorly and has ruptured at its anterior margin.

with a titre of 1:80. Her remaining biochemistry test results, including her liver functions, were normal. In addition, abdominal ultrasonography was performed. This showed a massive cystic collection in the right hypochondrium with numerous daughter cysts and associated ascites (Fig. 1).

The CT scan revealed a hepatic hydatid cyst with primary spillage into the parahepatic and paracolic spaces (Figs 2 a-c). 


\section{CASE REPORT}

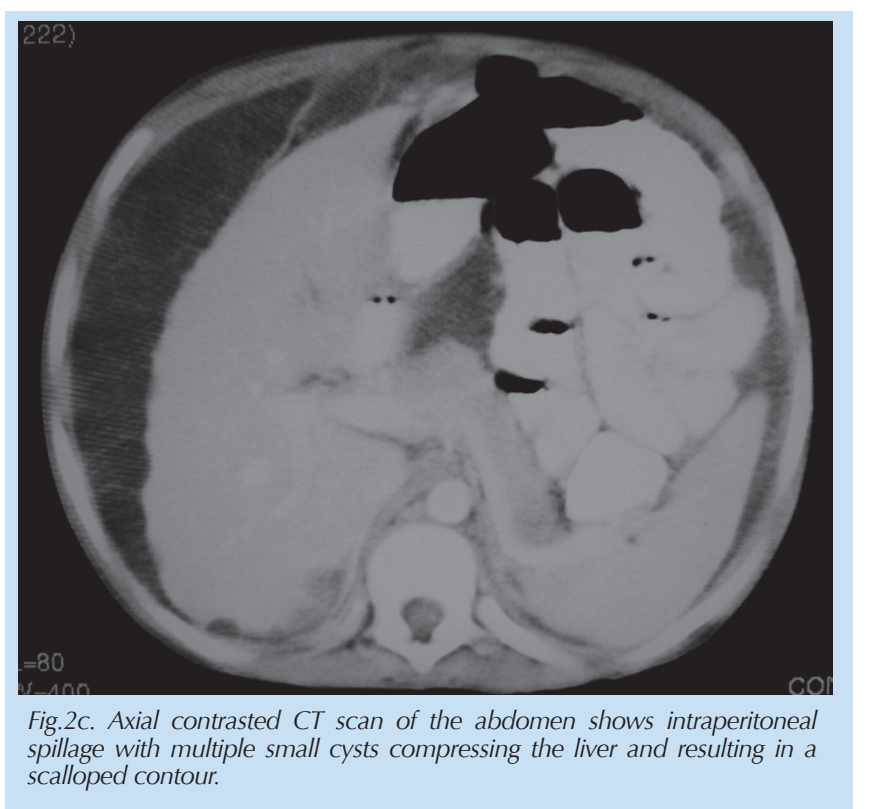

The patient was initially treated with albendazole, but her response was poor. After 2 weeks, the patient underwent surgery to remove the cyst. After surgery, her management once again included albendazole, after which she recovered well.

Rupture and spillage of hepatic hydatid cyst can lead to dissemination and anaphylaxis. This could prove to be fatal. ${ }^{2}$ The presenting condition of our patient may be termed encysted hydatidosis. ${ }^{3}$ Early surgical intervention is of paramount importance. ${ }^{4}$ Percutanous removal of cysts or injection by way of hypertonic saline solution, is successful in the management of encysted hydatidosis. ${ }^{5}$

1. Chrieki M. Echinococcosis - an emerging parasite in the immigrant population. Am Fam Physician 2002 . 5: $817-820$

2. Lahiri K. Parasitic infections of the respiratory tract. J Postgrad Med 1993; 39: 144-148.

3. Paksoy Odev K. Percutanous treatment of liver hydatid cysts. AJR 2005; 185: 727-734.

4. Wong LS. Hydatid liver disease as a cause of recurrent pancreatitis. J R Coll Surg Edinb 1999; 44: 407-409. 5. Bhat S. Transdiaphragmatic extension of hepatic hydatid cyst. Indian J Chest Dis Allied Sci 2002; 44: 1-4.

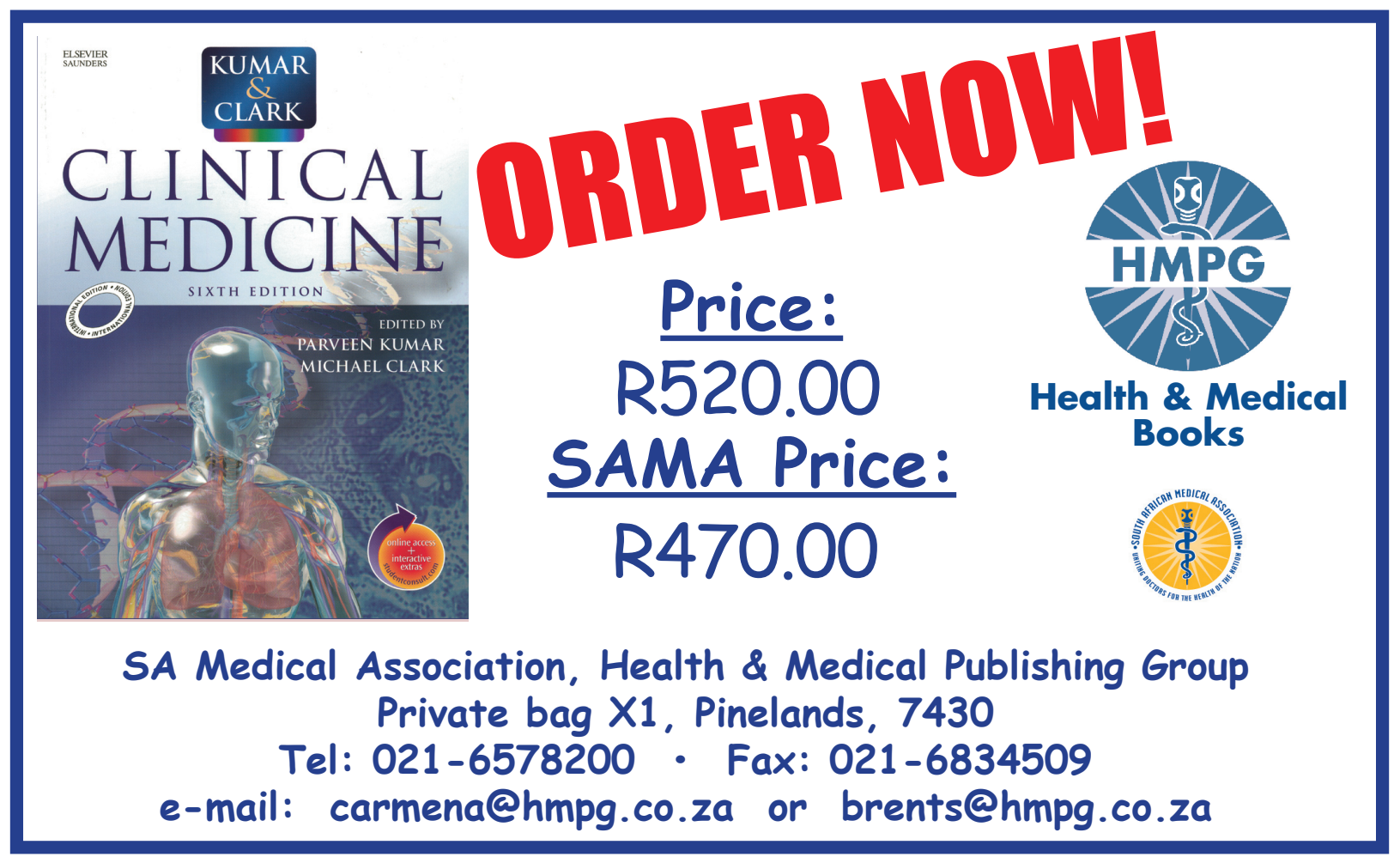

